\title{
Motivasyonel görüşmenin çocuk ve adölesanlarda kullanımı
}

\author{
İlknur YILDIZ ${ }^{1}$, Meral BAYAT ${ }^{2}$
}

\begin{abstract}
$\ddot{\mathbf{O z}}$
Sağlık davranışlarının kazanılmasında ve sürdürülmesinde çocukluk dönemi ve aile önemli rol oynar. Çocuk ve adölesanlarda riskli ya da olumsuz sağlık davranışlarının değiştirilmesinde ve tedaviye uyum sağlanmasında farklı girişimlere ihtiyaç duyulmaktadır. Davranış değişikliğinde etkin bir yaklaşım olarak görülen motivasyonel görüşme sağlığın korunması, hastalıkların tedavisi ve rehabilitasyonunda önemli yararlar sağlar. Motivasyonel görüşme değişim için içsel motivasyon sağlayan, bireyin kendi davranış değişim nedenlerini ortaya çıkaran işbirliğine dayalı bir yaklaşımdır. Çocuk ve aileye yönelik uygulamalarda motivasyonel görüşmenin kullanımı tedaviye uyumu kolaylaştırır. Çocuk sağlığı alanında çalışan sağllk profesyonellerinin motivasyonel görüşme konusundaki bilgi ve becerilerini arttırarak çocuk ve ailenin bakımında etkin şekilde kullanmaları önerilmektedir.
\end{abstract}

Anahtar Kelimeler: Adölesan, aile, çocuk, hemşirelik, motivasyonel görüşme
Yayın Bilgisi

Gönderi Tarihi:11.11.2017

Kabul Tarihi:14.02.2018

Online Yayın Tarihi:31.12.2018

DOI: $10.26453 /$ otjhs. 351343

Sorumlu Yazar

İlknur YILDIZ

\section{Using motivational interviewing in children and adolescents}

İlknur YILDIZ ${ }^{1}$, Meral BAYAT ${ }^{2}$

\begin{abstract}
Childhood period and family play an important role in the develop and maintenance of health behaviors. Different interventions are needed to change risky or negative health behaviors and adherence to treatment in children and adolescents. Motivational interviewing, seen as an effective approach to maintaining behavioral change, provides important benefits in the health protection, in the treatment and rehabilitation of diseases. Motivational interviewing is a collaborative approach that provides intrinsic motivation for change and revealing the individual's reasons for behavior change. The use of motivational interviewing in child and family practices facilitates adherence to the treatment. Health professionals who working with children are advised to increase the knowledge and skills of motivational interviewing and use them effectively in child and family care.
\end{abstract}

Article Info

Keywords: adolescent, family, children, nursing, motivational interviewing

Received:11.11.2017

Accepted:14.02.2018

Online Published: 31.12.2018

DOI: $10.26453 /$ otjhs. 351343

Corresponding Author

İlknur YILDIZ

\footnotetext{
${ }^{1}$ Cumhuriyet Üniversitesi Sağlık Bilimleri Fakültesi Hemşirelik Bölümü, Çocuk Sağlığı ve Hastalıkları Hemşireliği AD, SIVVAS

${ }^{2}$ Erciyes Üniversitesi, Sağlık Bilimleri Fakültesi Hemşirelik Bölümü, Çocuk Sağlığı ve Hastalıkları Hemşireliği AD, KAYSERİ
}

\section{GíRIŞ}

Birçok sağllk probleminin çözümü ve tedavisi davranış değiş̧ikliği yapmayı gerektirir.

Davranış değişikliği sağlamada tavsiye, ikna, eğitim gibi yöntemler yeterli olmayabilir. Değişime hazır ya da istekli olmayı ifade eden motivasyon, içsel bir durum olup, insan davranışlarında önemli rol oynar. ${ }^{1-5}$ Motivasyonu geliştirmede Motivasyonel Görüş̧e (MG)'den yararlanılabilir. MG, bireyin kendi davranış değişim nedenlerini ortaya çıkararak, değişim için isteksiz ya da dirençli olan bireylerin sorunlarını anlamalarını 
ve eyleme geçmelerini sağlar., ${ }^{6,7}$ Bireyin mantıklı ve ulaşılabilir amaçları geliştirmesini sağlayarak, değişime yönelik içsel motivasyonu arttırır. $^{5,8}$ Illk olarak W. Miller (1983) tarafından alkolizm tedavisi için geliştirilen $\mathrm{MG}$, daha sonra birçok mental ve fiziksel soruna yönelik olarak Miller ve Rollnick tarafından genişletilerek kullanılmıştır. ${ }^{6,7}$

Empatinin ifadesi, bireyin şimdiki davranışı ile tedavi amaçları arasında çelişkilerin giderilmesi, danışanın direnciyle çalışma, öz etkililiğin desteklenmesi MG'nin temel ilkeleridir. ${ }^{6,8,9}$ MG'de açık uçlu soru sorma, yansıtıcı dinleme, destekleme, özetleme, değişimi konuşma kullanılan temel etkileşim teknikleridir. ${ }^{6-8} \mathrm{MG}$, özellikle davranış değişimini sağlamak için etkisi kanıtlanmış teknik ve becerilerle tıbbi uygulamalar için oldukça uygundur. ${ }^{10}$ Sağlık sorunlarının tedavisinde iş yükü, zaman kısıtlılığı, bireyin değişime dirençli olması, koruma yerine tedavi odaklı çalışılması, iletişim problemleri, bilgi eksikliği ve ekonomik sorunlardan dolayı davranış değişikliği hemen görülmeyebilir., ${ }^{9,1}$ Sağlık bakım uygulamalarına MG tekniği eklenmesinin bireyin uyumunda artışla birlikte sağlık sonuçlarında önemli düzelmeler sağladığı bildirilmektedir., ${ }^{9,10,12}$ Danışan merkezli ve işbirlikçi yaklaşımı benimseyen MG'nin kisa sürede tedaviye uyumu arttırdığı ve olumlu sağlık davranışları geliştirmeye katkı sağladığ belirtilmektedir. ${ }^{7-13}$ Yapılan bazı çalışmalarda MG'nin alkol-madde kullanımı ${ }^{14}$, kilo kontrolü ${ }^{15}$ ve Tip 2 diyabet $^{16}$ tedavisinde etkili olduğu bulunmuştur. Madde kullanım bozukluklarında bir-iki seans uygulanan MG'nin davranışı bırakma yönünde kalıcı etkilerinin olduğu belirlenmiştir. ${ }^{3,17}$ Davranış değişikliği sağlamada kısa ve etkili bir yöntem olan MG'nin sağlık bakım hizmetleriyle birleştirilmesinin $\quad$ yararlı olacağı belirtilmektedir.9,10,18 MG eğitimi alan hemşirelerle yapılan bir çalışmada, hemşireler MG'nin hastalar ve hemşireler açısından kolaylaştırıcı ve yararlı bir uygulama olduğunu ifade etmiştir. ${ }^{19}$ Sağlığın geliştirilmesi ve hastalıkların önlenmesinde önemli rolleri olan hemşirelerin çocuk ve ailenin bakımında MG'yi kullanmasının çocuğun ve ailenin sağlığına olumlu katkılar sağlayacağı düşünülmektedir. $\mathrm{Bu}$ derlemede çocuk ve adölesanlarda motivasyonel görüşmenin etkileri incelenmiş ve tartışılmıştır.

\section{Çocuk, Aile ve Motivasyonel Görüşme}

Olumlu sağlık davranışlarının kazanılmasında ve sürdürülmesinde çocukluk dönemi ve aile önemlidir. Sağlık sorunlarının tedavisi ve kronik hastalıkların yönetiminde çocukların önerilen tedavilere uymaması veya ebeveynlerin çocuklarına yeterli bakımı verememesi olumsuz sonuçlara yol açar. ${ }^{8,20}$ Birçok sağl1k sorunu çocuğun ve ailenin alabileceği bazı önlemler ile tedavi edilebilir. Ancak yalnızca ikna etmeye odaklı yaklaşımlar dirence neden olarak davranış değişikliği sağlamada yetersiz kalabilir. ${ }^{2}$ Cleveland (2005) sağlık sorunlarının çözümünde davranış değișikliği olmamasının 
nedenlerini; çocuğun gelişimsel düzeyi, ailenin tedavi planına katılmaması, çocuğa verilen tedavinin etkileri konusunda ebeveynlerin şüpheleri, çocuk ve ailenin isteksizliği, durumsal engeller, aileye verilen desteğin yetersizliği olarak belirtmiştir. Ailenin çocuğun hayatındaki rolünü ve katılımını ifade eden aile merkezli bakım, ebeveyn ile sağlık çalışanı arasında etkin iletişimi gerektirir. ${ }^{21}$ Davranış değişimi sağlamak amaciyla yapılan uygulamalarda çocuğun ailesiyle kurulan terapötik iletişimin tedavi üzerine etkileri dikkat çekicidir. ${ }^{10}$ Çocuk sağlığı alanında çalışan sağlik profesyonellerinin terapötik iletişim yoluyla davranış değişimi sağlamaya yönelik planlamalar yapması ve etkili müdahaleler geliştirmesi gerekir. ${ }^{10} \mathrm{Bu}$ amaçla değişimin önemli ve ihmal edilen bileșeni olan motivasyona odaklanılmalı ve tedaviye ebeveynlerin katılım ve desteği sağlanmalıdır. ${ }^{20}$ Çocuk ve ailenin davranışa yönelik motivasyonu değerlendirilerek, değişimin hem çocukta hem de ebeveynlerde olması sağlanmalıdır. ${ }^{2}$ Lask $^{20}$ pediatri kliniklerinde motivasyon arttırıcı tekniklerin büyük yararlar sağladığını, Erikson ${ }^{8}$ pediatrik uygulamalarda MG'nin davranış değişikliği sağlamada etkili bir yaklaşım olduğunu belirtmiştir. Son yıllarda literatürde MG'nin pediatrik uygulamalarda etkisine yönelik çalışmalar artmıştır. Obezite, diyabet, astım gibi hastalıklarda MG'nin etkili olduğu ve tedavi sonuçlarında düzelmeler sağladığı bulunmuştur. ${ }^{22-25}$ Willgerodt ve ark. ${ }^{26}$ motivasyona dayalı müdahalenin okul çağı çocuklarda uyku örüntülerini değiştirdiğini belirtmiștir.

Bütüncül ve aile merkezli yaklaşımı benimseyen MG'nin çocuk ve ebeveynleriyle yakınlık kurmayı sağladığı; tedavi, koruma ve bakım gibi süreçlere ailenin katılımını desteklediği belirtilmektedir. $^{8}$ Borelli ve ark. ${ }^{27}$ çocuk ve ebeveynlerle yapılan MG'nin sağlık davranışlarında düzelme sağladığını ve ebeveyn-çocuk ikilisine odaklanan girişimlerin yalnızca çocuk veya yalnızca ebeveyne yönelik girişimlerden daha etkili olduğunu belirtmiştir. Bunun nedenini müdahalenin sadece bir çocuğu değil, ailedeki diğer çocukları da etkilemesi olarak açıklamıştır. ${ }^{27}$ Saelens ve ark. ${ }^{28}$ çalışmasında pediatrik obezite tedavisinde $\mathrm{MG}$ içeren aile temelli davranıșsal yaklaşımların etkili olabileceğini belirtmiștir. Yapılan çalışmalarda obezite, pasif içicilik, fiziksel aktivite gibi alanlarda çocuklarla birlikte ebeveynlerin dahil olduğu MG müdahalelerinin davranış değişiminde etkili olduğu bulunmuştur. ${ }^{19-22}$ Pediatrik uygulamalarda motivasyon odaklı kısa ve etkili müdahalelerin kullanımı sağlıkla ilgili davranışsal, gelişimsel ve sosyal problemlerden korunmayı sağlayarak, erken müdahale ile tedavinin hızlı bir şekilde planlanmasını sağlar. ${ }^{8}$ Geçmişte çocuk, adölesan ve aileye verilen bakımda davranışsal ve psikososyal açıdan eksikler olduğu, MG'nin destekleyici ve empatik bir yaklaşımla sağlık sorunlarının tartışılmasını kolaylaştırdığı ve 
teşvik edici bir yaklaşım olduğu yandan riskli davranışlara eğilimi arttırabilir, belirtilmektedir. $^{8,10,17,33}$ Malas ve ark. $^{34}$ nın diğer bir yandan da olumsuz davranışları çalışmasında pediatri uzmanlık eğitimi sırasında değiştirmek için fırsat sağlar. ${ }^{36}$ Çünkü verilen dört saatlik MG eğitiminin; asistanların adölesanlar yetişkinler gibi riskli veya olumsuz sağlık davranışı değiştirmede, kendilerine olan bir davranışın fiziksel ve psikososyal güveni ve empatik dil kullanımını arttırdığı sonuçlarını henüz yaşamamıştır. ${ }^{10}$ Adölesanın belirlenmiştir. Yapılan bir meta analiz ambivalansı ve bireysel seçimlerini kabul eden çalışmasında MG'nin kilo kontrolü, uyku, egzersiz gibi sağlığ geliştirici davranışların kazanılmasında olumlu etkiler sağladığ çocukların davranış değişimde etkin ve uygun bir yaklaşım olduğu bulunmuştur. ${ }^{35}$ Davranışsal bir müdahale olarak MG'nin sağl1kl1/hasta çocuğun tedavisi ve bakımında çalışan sağlık profesyonelleri tarafindan kullanımı önerilmektedir. ${ }^{2}$ Cleveland (2005) hemşirelerin MG tekniğini kullanarak çocuğa ve aileye danışmanlık sağlamasının sağlıklı yaşam alışkanlıklarının kazanılmasında ve bakımda önemli yararlar sağlayacağını belirtmiştir. $\mathrm{Bu}$ amaçla hemşire, çocuk ve ailenin özelliklerini değerlendirerek, MG'nin direnci azaltan ve etkileşimi teşvik eden ilkelerini bakımında uygulamalıdır.

\section{Adölesan ve Motivasyonel Görüşme}

Adölesan dönem bebeklikten sonra en fazla biyolojik, bilişsel ve sosyal değişimlerin olduğu, otonomi ve kimlik kazanımı ile karakterize bir dönemdir. ${ }^{10,36}$ Erikson'un Psikososyal Gelişim Kuramı'na göre adölesan bu dönemde kimlik gelişimine karşın rol karmaşası ve yoğun ambivalans yaşar, otoriteye meydan okur, otonomisini kurmaya çalışır. ${ }^{10} \mathrm{Bu}$ değişimler bir MG, değişim için motivasyon sağlar. $\mathrm{MG}$, adölesanın gelişimsel değişimlerini, kendi davranışları hakkındaki doğru ve değiştirilemeyen yeteneklerini ve otonomisini kabul ederek riskli ve olumsuz davranışlarını değiştirmeye çalışır. Daha gerçekçi ve ulaşılabilir amaçlarla problemli davranışın azalmasını sağlar, tedaviye uyumu arttırır. ${ }^{7,10,36,37} \mathrm{Bu}$ nedenle MG'nin adölesanlarda kullanımının uygun olduğu belirtilmektedir.

MG'nin adölesanların ihtiyaçlarına cevap verecek nitelikte çok yönlü, yeterli ve uygulanabilir olduğu, bu nedenle yaşanan mental ve fiziksel sorunların çözümünde etkili olduğu $\quad$ belirtilmektedir. ${ }^{10,36} \quad$ Yapilan çalışmalarda; MG'nin adölesanlarda sigara, alkol, ilaç kullanma davranışlarını azalttığı ve adölesanın fiziksel ve zihinsel sağlığına olumlu katkılar sağladığı bulunmuştur. ${ }^{36-40}$ Knight ve ark. $^{41}$ diyabet kontrolü yetersiz olan 20 adölesanla yapılan MG'nin adölesanlarda kabul ve kontrol duygularını arttırarak diyabet algısında pozitif değişimler sağladığını belirtmiştir. Walpole ve ark. ${ }^{42}$ aşırı kilolu veya obez 10-18 yaş grubu çocuk ve adölesanlara 
uygulanan MG'nin, sağlık davranışlarına olumlu katkı sağladığını, Berg-Smith ve ark. ${ }^{43}$ MG ve kısa görüşmelerin, diyette kolesterol ve yăg alımını azalttığını, Chen ve ark. $^{44}$ HIV/AIDS'li gençlerde riskli cinsel davranışları önlediğini, Naar- King ve ark. $^{45}$ HIV/AIDS tedavisine uyumu desteklediğini belirtmiştir. Tip 1 diyabetli adölesanlarla yapılan bir çalışmada ise MG'nin iyilik hali ve yaşam kalitesini arttırdığı, HbA1C düzeyini düşürdüğü bulunmuştur. ${ }^{46}$ Riekert ve ark. ${ }^{47}$ MG'nin astımlı adölesanlarda tedaviye uyumu arttırdığını ve olumlu değişimler sağladığını belirtmiştir. Ülkemizde yapılan bir çalışmada adölesanlarda değişim aşamalarına dayalı MG'nin sigara bırakmada etkili olduğu bulunmuştur. ${ }^{48}$ Yurt $^{49}$ çalışmasında MG'nin kilolu adölesanların kilo vermelerinde etkili olduğu, beslenme ve egzersizle ilgili tutum ve davranışları olumlu yönde etkilediği saptamıştır. Astımlı adölesanlara yapılan bir çalışmada da MG'nin astım kontrolünü ve öz etkililiği arttırdığ belirlenmiștir. ${ }^{50}$

MG, adölesanlarda değişimi ortaya çıkaran öz etkililiğin artmasında etkilidir. Destekleyici, esnek, bireysel farklılıkları araştıran, açık, otonomiyi destekleyen bir yöntem olarak MG adölesanların bağımsızlık isteği, kimlik gelişimi gibi gelişimsel özellikleriyle örtüşür. ${ }^{26}$ Ayrıca adölesanların ebeveynlerine yönelik bir müdahale olarak da kullanılabilir. ${ }^{8}$ Adölesanlarla yapılan görüşmelerde bağımsızlık, aile ilişkileri, destek kaynakları değerlendirilmeli ve MG uygulamalarına adölesanla birlikte ebeveynlerin katılımı da sağlanmalıdır. ${ }^{37}$ Aşırı kilolu ve obez adölesanlarda dislipidemi yönetimine ilişkin yapılan bir çalışmada bir grup adölesanla yalnız, bir grup adölesanla ebeveynleriyle birlikte MG yapılmış ve her iki grupta da MG'nin sağlıklı yaşam tarzının kazanılmasında ve fizyolojik değişikliklerde etkili bir strateji olduğu bulunmuştur. ${ }^{51}$ Hemşireler gelişim teorilerini temel alarak ve adölesanların gereksinimlerini belirleyerek terapötik bir müdahale yöntemi olarak MG'yi kullanabilir ${ }^{37}$ Hemşirenin adölesan sağlığı alanında MG'yi kullanması, olumlu tedavi sonuçlarının yanı sıra hasta hemşire iletişimini geliştirmektedir. $\mathrm{Bu}$ nedenle adölesanlarda MG kullanımı bireysel ve grup çalıșması şeklinde

planlanarak yaygınlaştırılabilir.

\section{SONUÇ}

Davranış değişiminde ve tedaviye uyum sağlamada olumlu sonuçlar sağlayan $\mathrm{MG}$, çocuk/adölesan sağlığını geliştirmede, hastalıkların önlenmesinde ve rehabilitasyonunda kullanılabilir. Birey merkezli ve işbirlikçi yaklaşımı benimseyen MG uygulamalarına ailelerin dahil edilmesi, hem çocuk hem de ailedeki davranış değişimi süreci açısından önemlidir. Çocuk sağlı̆̆ alanında çalışan sağlık profesyonelleri $\mathrm{MG}$ tekniği konusundaki bilgi ve becerilerini artırarak, aile ile işbirliği yaparak bu tekniği 
çocuk ve adölesanın bakımında aktif bir şekilde kullanmalıdır. Ayrıca çocuk ve adölesanlarda MG'nin kullanımına yönelik kapsamlı araştırmalar yapılması önerilebilir.

\section{KAYNAKLAR}

1. Britt E, Hudson SM, Blampied NM. Motivational interviewing in health settings: a review. Patient Educ Couns. 2004 53(2):147-55.

2. Gance-Cleveland

B. Motivational interviewing: Improving patient education. Journal of Pediatric Health Care 2007; 21: $81-88$

3. Rubak S, Sandbaek A, Lauritzen T, et al. Motivational interviewing: A systematic review and meta-analysis. BJGP 2005; 55: 305-312.

4. Ögel K. Motivasyonel görüşme tekniği. Türkiye Klinikleri Psychiatry-Special Topics 2009; 2(2):41- 4

5. Işı1 Ö. Motivasyon ve Davranış Değişikliğinde Ailenin Rolü. Kuğuoğlu S, Demirbağ BC (ed) Aile Temelli Sağlik Yaklaşımı. Akademisyen Tıp Kitabevi, Ankara, 2015: ss 121-133.

6. Miller WR, Rollnick S. Motivational interviewing: Preparing people for change. second edition. New York, Guilford Press, 2002: ss 123-129.

7. Miller WR, Rollnick S. Motivasyonel Görüşme Bağlam, Pratik, Uygulamalar. Karadağ F, Ögel K, Tezcan AE. (Çev),
Motivasyonel Görüşme. Hekimler Yayın Birliği, Ankara, 2009: ss 40-104.

8. Erickson SJ, Gerstle M, Feldstein SW. Brief interventions and motivational interviewing with children, adolescents, and their parents in pediatric healthcare settings. Arch Pediatr Adolesc Med 2005; 159: 1173-1180.

9. Bisonó AM, Manuel JK, Forcehimes A.A. Promoting Treatment Adherence Through Motivational Interviewing. https://www.corwin.com/sites/default/files/u pm-binaries/11867_Chapter_5.pdf. Erişim Tarihi: 16 Haziran 2015

10. Sindelar HA, Abrantes AM, Hart C, et al. Motivational interviewing in pediatric practice. Curr Probl Pediatr Adolesc Health Care 2004; 34: 322-339.

11. Lambe B, Collins C. A qualitative study of lifestyle counselling in general practice in Ireland. Fam. Pract. 2010; 27:219-223.

12. Lundahl B, Kunz C, Brownell C, et al. A meta-analysis of motivational interviewing: Twenty-five years of empirical studies. Res Soc Work Pract 2010;20: 137-160.

13. Hettema J, Steele J, Miller WR. Motivational interviewing. Annu Rev Clin Psychol. 2005; $1: 91-111$

14. Stephens R, Roffman R, Curtin L. Comparison of extended versus brief treatments for marijuana use. JCCP 2000; 68: 898-908.

15. Smith D, Heckemeyer C, Kratt P, et al. Motivational interviewing to improve 
adherence to a behavioral weight-control program for older obese women with NIDDM: A pilot study. Diabetes Care 1997; 20: 53-54.

16. Chen SM, Creedy D, Lin HS, et al. Effects of motivational interviewing intervention on self-management, psychological and glycemic outcomes in type 2 diabetes: A randomized controlled trial. IJN 2012; 49: 637-644.

17. Burke BL, Arkowiz H, Mechola M. The efficacy of motivational interviewing: ametaanalysis of controlled clinical trial. J Consult Clin Psych 2003;71:843-61.

18. Soderlund LL, Madson MB, Rubak S, et al. A systematic review of motivational interviewing training for general health care practitioners. Patient Educ. Couns. 2011; 84:16-26.

19. Östlund AS, Wadensten B, Kristofferzon ML, et al. Motivational interviewing: experiences of primary care nurses trained in the method. Nurse Educ Pract. 2015;15(2):111-8.

20. Lask B. Motivating children and adolescents to improve adherence. J Pediatr 2003; 143: 430-433.

21. Conk Z, Başbakkal Z, Yardımcı F. Çocuk Sağlığına Genel Bakış. Conk Z, Başbakkal Z, Balyılmaz H, Bolışık B (Ed), Pediatri Hemşireliği. 1. Baskı, Akademisyen Tıp Kitabevi, Ankara, 2013.
22. Resnicow K, Davis R, Rollnick S. Motivational interviewing for pediatric obesity: conceptual issues and evidence review. J Am Diet Assoc. 2006; 106:202433.

23. Wong EMY, Cheng MMH. Effects of motivational interviewing to promote weight loss in obese children. J Clin Nurs. 2013; 22:2519-30

24. Stanger C, Ryan SR, Delhey LM, et al. A multicomponent motivational intervention to improve adherence among adolescents with poorly controlled type 1 diabetes: a pilot study. J Pediatr Psychol. 2013; 38:629-637.

25. Halterman JS, Szilagyi PG, Fisher SG, et al. Randomized controlled trial to improve care for urban children with asthma: results of the school-based asthma therapy trial. Arch Pediatr Adolesc Med. 2011; 165:262-8.

26. Willgerodt MA, Kieckhefer GM, Ward TM, et al. Feasibility of using actigraphy and motivational-based interviewing to improve sleep among school-age children and their parents. J Sch Nurs 2014; 30: 136-148.

27. Borrelli B, Tooley EM, Scott-Sheldon LA. Motivational interviewing for parent-child health interventions: a systematic review and meta-analysis. Pediatr Dent. 2015;37(3):25465.

28. Saelens BE1, Lozano P, Scholz K. A randomized clinical trial comparing delivery of behavioral pediatric obesity treatment using standard and enhanced motivational 
approaches. J Pediatr Psychol. 36. Naar-King S. Motivational interviewing in

2013;38(9):954-64.

29. Davoli AM, Broccoli S, Bonvicini L, et al.

Pediatrician-led motivational interviewing to treat overweight children: an RCT. Pediatrics 2013;132:1236-1246.

30. Haines J, McDonald J, O'Brien A, et al. Healthy Habits, Happy Homes: randomized trial to improve household routines for obesity prevention among preschool-aged children. JAMA Pediatr 2013;167:1072-9.

31. Harutyunyan A, Movsisyan N, Petrosyan V, Petrosyan D, Stillman F. Reducing children's exposure to secondhand smoke at home: a randomized trial. Pediatrics 2013;132:107180 .

32. Barkin SL, Gesell SB, Poe EK, Ip EH. Changing overweight Latino preadolescent body mass index: the effect of the parentchild dyad. Clin Pediatr (Phila) 2011;50:2936.

33. Suarez M, Mullins S. Motivational interviewing and pediatric health behavior interventions. J Dev Behav Pediatr. 2008; 29:417-28.

34. Malas N, Rofey D, Kuchera AM, Pletcher J, Ortiz-Aguayo R, Douaihy A, Gold M. Motivational interviewing in paediatric residency. Clin Teach. 2017;14(1):20-26.

35. Gayes LA, Steele RG. A meta-analysis of motivational interviewing interventions for pediatric health behavior change. J Consult Clin Psychol 2014;82:521-35. adolescent treatment. Can J Psychiatry 2011; 56: 651-657.

37. Jackman K. Motivational interviewing with adolescents: an advanced practice nursing intervention for psychiatric settings. Journal of Child and Adolescent Psychiatric Nursing 2012; 25: 4-8.

38. D'amico E, Miles JNV, Stern SA, et al. Brief motivational interviewing for teens at risk of substance use consequences: A randomized pilot study in primary care clinic. J. Subst Abuse Treat 2008; 35: 53-61.

39. Spirito A, Monti PM, Barnett NP, et al. A randomized clinical trial of a brief motivational intervention for alcohol-positive adolescents treated in an emergency department. J Pediatr 2004; 145: 396-402.

40. Colby SM, Monti PM, O’Leary TT, et al. Brief motivational intervention for adolescent smokers in medical settings. Addict Behav 2005; 30: 865-874.

41. Knight KM, Bundy C, Morris R, et al. The effects of group motivational interviewing and externalizing conversations for adolescents with Type-1 diabetes. Psychology, Health \& Medicine 2003; 8: $150-157$.

42. Walpole B. Dettmer E, Morrongiello B, et al. Motivational interviewing as an intervention to increase adolescent self-efficacy and promote weightloss: Methodology and 
design. BMC Public Health 2011; 11: 459467.

43. Berg-Smith SM, Stevens VJ, Brown KM, et al. A brief motivational intervention to improve dietary adherence in adolescents. Health Educ Res Theory Pract 1999; 14: 399-410.

44. Chen X, Murphy DA, Naar-King S, Parsons JT. Adolescent medicine trials network for HIV/AIDS interventions a clinic-based motivational intervention improves condom use among subgroups of youth living with HIV. J Adolesc Health. 2011; 49:193-8.

45. Naar-King S, Outlaw AY, Saar M, et al. Motivational enhancement system for adherence (MESA): pilot randomized trial of a brief computer-delivered prevention intervention for youth initiating antiretroviral treatment. J Pediatr Psychol. 2013; 38:63848.

46. Channon SJ, Huws-Thomas MV, Rollnick S, et al. A multi center randomized controlled trial of motivational interviewing in teenagers with diabetes. Diabetes Care 2007; 30: 1390-1395.
47. Riekert KA, Borrelli B, Bilderback A, et al. The development of a motivational interviewing intervention to promote medication adherence among inner-city, African-American adolescents with asthma. PEC 2011; 82: 117-122.

48. Erol S, Erdogan S. Application of a stage based motivational interviewing approach to adolescent smoking cessation: The Transtheoretical Model-based study. PEC 2008; 72: 42-48.

49. Yurt S. Fazla Kilolu Adölesanlara Uygulanan Motivasyon Görüşmelerinin Beslenme Tutumu, Davranışları ve Kilo Üzerine Etkisi. Marmara Üniversitesi Sağlık Bilimleri Enstitüsü Halk Sağlığı Hemşireliği AD, Doktora Tezi, İstanbul, 2008: 76-78.

50. Y1ldiz İ, Bayat M. Effect of motivational interviewing on asthmatic adolescents. SYLWAN Journal 2017;161(8):315-332.

51. Chahal N, Rush J, Manlhiot C, et al. Dyslipidemia management in overweight or obese adolescents: A mixed-methods clinical trial of motivational interviewing. SAGE Open Medicine 2017;5: 1-15. 